Coming now to the method of making observations and the observations themselves, a word of warning should be given to those who are not familiar with making solar observations. No one should use a pair of binoculars or a telescope of any size unless proper precautions are taken; otherwise the loss of eyesight may be the result. It is better to make no attempt to watch the transit than to make risky observations. Proper dark glasses should be secured beforehand, and fixed firmly in position so that they cannot fall off at the critical time. A method devoid of all risk is to throw the solar image on a screen; in this way more than one observer can watch the transit.

In the Comptes rendus of the Paris Academy of Sciences for October 5 Monsieur Bigourdan summarises a series of the principal precautions which should be taken by those who wish to make useful observations. Such precautions are necessary because a transit of Mercury seems to be accompanied by various appearances the causes of which are not always well known. It is therefore advisable to eliminate so far as possible all possible errors which may arise through instrumental deficiencies.

He suggests first of all the method of observing the sun directly, and not by projection, for in the latter case delicate details are chiefly lost. To diminish the solar light he proposes a method of semi-silvering the outer surface of the objective, but he adds that this method holds good only when the sky is clear, otherwise observation would be impossible. The practical method of employing graduated and compensated dark glasses is chiefly recommended, and the greatest aperture of the telescope should be employed, having due regard to the heating at the focus, and the resulting cracking of the graduated glass.

While giving the preference to telescopes of large aperture, the results furnished by moderate or even small telescopes should not be neglected. Both reflectors and refractors should be brought into use. He directs attention to the importance of having diaphragms well blackened and suppressing for the time being any fixed accessories in telescopes which ordinarily serve for the illumination of the field, and which, situated in the path of the beam or in the vicinity of it would produce hurtful reflections. When an instrument can be reversed or can take up two positions successively to the right and left of its mounting, it should be utilised alternately in these positions, thus turning the whole optical system through $180^{\circ}$. Finally, he points out the importance of observing every appearance, however abnormal, by studying it in different positions of the telescope, with different eyepieces, dark glasses, etc. While the above precautions are particularly to be recommended for accurate observations, others of a secondary nature must not be forgotten.

With regard to the observations to be made during the planet's transit, those of first importance are the determinations of the accurate time of the internal and external contacts. Next come the measurements for the determination of the diameter and the flattening of the planet's disc. Rings (aureoles) around the black disc of Mercury form interesting objects for observation, and their intensity in relation to the neighbouring solar surface should be studied.

A spectroscopic survey of these rings would decide whether their existence was real or not, and the question of an atmosphere round Mercury could thus possibly be inquired into. Other points of interest relate to luminous appearances on the dark disc of the planet, possibility of satellites, occultations of solar spots, and faculæ by the disc, etc.

Successful observations of these and other phenomena help to further our knowledge of the movements and physical constitution of this the smallest of the planets.

\section{A METEORITIC FALL IN LANCASHIRE}

ON Tuesday evening, October I 3 , at 8.45, the inhabitants of Lancashire and Cheshire were alarmed by a sudden and vivid illumination of the heavens caused by a ball of fire moving slowly from about S.S.E. to N.N.W. It lit up the whole countryside and consisted of several outbursts, the final one being the brightest flash. Then a short interval afterwards, the estimated periods varying from a few seconds to four minutes, according to the distances of the observers, there was a tremendous report, as though a thunder-like explosion had occurred in the region a few miles west of Wigan.

This was followed by a series of rumblings extending apparently back along the flight of the luminous object. At several places the windows are stated to have been shaken, and the vibration was such that it presented some similarity to an earthquake shock.

Numbers of persons in Manchester, Liverpool, Halifax, Northwich, Bolton, Macclesfield, and other towns witnessed the event and heard the noise, and in the present agitated state of the public mind, all sorts of ideas were formed as to the nature of the phenomenon.

A large detonating meteor had, notwithstanding the rather cloudy state of the atmosphere, not only penetrated the lower region of the air, but had resisted complete disruption and fallen to the ground. It was discovered on the following day at Appley Bridge, four miles W.N.W. of Wigan. An employee of $\mathrm{Mr}$. Lyon of Halliwell Farm noticed a newly turned up mound in a field and, on examination, he saw a reddish mass of strange material lying in a hole about $\mathrm{I} 8$ in. below the surface. On being dug out the object weighed about 33 lbs. and in appearance looked like a rough piece of burnt iron. Subsequently, the county police took possession of the strange visitor, and it has since been handed over to the curator of the Grodlee Observatory, Manchester, for proper investigation.

NO. 2349, VOL. 94] 
My preliminary discussion of the first observations received indicated that the meteor penetrated to a point so low in the air that it probably fell in the region twenty miles west of Manchester. This conclusion was mentioned in a letter to the Manchester papers, and the discovery of the meteorite a few miles west of Wigan fully justified the prediction. Several of the observers say that the object lost its luminosity when still at an apparently considerable height. This appears to show that the motion had so far slackened that combustion had visibly ceased, and the object fell to the ground in an opaque, cooling condition. Evidence of this is also furnished by its penetrating the soil to a depth of only is in. Several well-observed meteoritic falls have been of merely terrestrial velocity amounting to 400 or $500 \mathrm{ft}$. a second, which is something different from the velocity of 26 miles a second possessed by these bodies in planetary space. The descent of objects of this class is often vertical or nearly so, and their original velocity and direction are apparently quite changed by the new conditions impressed on them during their disruption when very near the earth's surface.

I have collected a large number of observations of the flight of the object, from which it appears that its direction was from about azimuth $335^{\circ}$, counted west from south, or from S.S.E. to N.N.W., and the probable radiant was at $34^{\circ}+2^{\circ}$ in the western region of Pisces. The course of the meteor was from near Stoke to the place of its fall, a length of 49 miles traversed at a velocity of about 8 miles a second. The height declined from 29 miles to $o$.

The object is said to have made a slanting hole in the ground, and this would accord with an angle of some $37^{\circ}$, which a radiant at $34^{\circ}+2^{\circ}$ would indicate. But the angle of the meteor's descent must have probably become much steeper after its entry into our atmosphere as an effect of the resistance encountered and terrestrial attraction. Several disruptions of its material undoubtedly occurred before the final outburst; these reduced the size and varied the shape of the object and may well have influenced the line of flight.

The radiant in Pisces yields many fireballs in September, and one was seen by many observers on September 8 last. Daniel's comet of I907 has an orbit which approaches near the earth's orbit on September iz and may possibly be responsible for some of the large meteors observed in September and at a later period.

Previous meteoric falls have occurred as follows in England, and I give the last recorded case in Ireland :-

I795 December 13, Wold Cottage, 56 lbs.

I830 February I5, Launton.

I835 August 4, Aldsworth.

1876 April 20, Rowton, $7 \frac{3}{4}$ lbs.

I88I March 14, Middlesbrough, $3 \frac{1}{2} \mathrm{lbs}$.

I902 September 3 $_{3}$, Crumlin, Ireland, $9 \frac{1}{2} \mathrm{lbs}$. W. F. Denning.

\section{NOTES.}

A COURSE of twelve Swiney lectures on geology will begin on Saturday, November ${ }_{14}$, in the lecture theatre of the Victoria and Albert Museum, South Kensington, by Dr. J. D. Falconer, who will take as his subject, "Land Forms and Landscapes." There will be no charge for admission to the course.

M. Bourroux, member of the Institute of France, and professor in the University of Paris, has accepted an invitation of the British Academy to deliver the first of the recently endowed annual philosophical lectures. His subject will be "Certitude et Verité," and the lecture will probably be delivered early in December next.

Announcement is made that the Serbian Government is in immediate need of the services of qualified bacteriologists and physicians experienced in the treatment of epidemic diseases. Conditions of service and remuneration will be made by arrangement. Applicants should communicate with the Secretary of the Serbian Legation, 195 Queen's Gate, London, S.W.

A SHARP earthquake was felt over the whole of northern Italy at 10.20 a.m. (9.20 Greenwich mean time) on October 27. The scanty reports which have appeared in the newspapers show that it was sensible from Venice to Elba, and from Turin to Ancona-that is, over an area of not less than 70,000 square miles. The epicentre was apparently near Lucca, or between that city and Bologna.

Col. W. B. Bryan, who, as chief engineer of the Metropolitan Water Board, had much to do with the improvement of the London water supply, died suddenly on October 27. Col. Bryan was to have delivered the Thomas Hawksley lecture on "Pumping and other Machinery for Waterworks and Drainage," before the Institution of Mechanical Engineers on Friday last, but the lecture has now been cancelled.

Dr. F. B. POWER will retire from the directorship of the Wellcome Chemical Research Laboratories on December $\mathrm{I}$, in order to return to the United States of America. His period of service dates from the foundation of these laboratories by Mr. H. S. Wellcome in the spring of 1896 . Dr. Power will be succeeded by Dr. F. L. Pyman. The character and policy of the Wellcome Chemical Research Laboratories will con. tinue as in the past.

A Reuter message from Stockholm reports that the Swedish scientific institutions which have to award the Nobel prizes in December have decided, in view of the European situation, to postpone the distribution of the prizes for 1914 for literature, medicine, chemistry and physics until next year. It is now proposed to hold the formal presentation of the prizes every year in the month of June instead of on December Io, the anniversary of M. Nobel's death, when the awards will merely be announced.

A GENERAL discussion on the hardening of metals has been arranged by the Faraday Society, to be held on Monday, November 23, at the Chemical Society, Burlington House, London, W. The president, Sir

No. 2349, voL. 94] 